\title{
Research on the Influence of Website Characteristics on Consumers' Impulsive Purchase Intention
}

\author{
Shengnan Liu* \\ School of Business Administration \\ Zhejiang Gongshang University \\ Hangzhou, China, 310000
}

\author{
Liang Xiao \\ School of Business Administration \\ Zhejiang Gongshang University \\ Hangzhou, China, 310000
}

\begin{abstract}
This article explores the factors that influence the impulse buying intention of mobile cross-border imported ecommerce platform consumers based on the theories of environmental psychology and impulsive buying. The website characteristics of the mobile cross-border imported e-commerce platform are classified into economical, personalized, socialized and interesting by combining with previous research. The consumer' sentiment is divided into pleasure and arousal. 15 relevant hypotheses are proposed through theoretical derivation to build a conceptual model of consumers' impulse buying intention of mobile cross-border imported e-commerce platform, which provides a theoretical basis for follow-up empirical research.
\end{abstract}

Keywords-website characteristics; pleasure; arousal; online impulse buying intention

\section{INTRODUCTION}

The mobile cross-border imported e-commerce platform has become an important way for Chinese consumers to buy imported goods online with the rapid development of mobile Internet technology and the continuous maturation of the crossborder e-commerce model [1]. However, unlike general online purchase behavior, mobile cross-border online purchase behavior has the following characteristics: (1)Relatively speaking, consumers lack understanding of foreign goods. (2)Online buying behavior presents fragmented buying features (3)Consumers are more sensitive to price discounts for high prices of imported goods. The above characteristics make it very important for mobile cross-border imported e-commerce platforms to create effective website features for consumers.

Research shows that online consumers are more impulsive than offline consumers [2]. At present, there are few studies on online impulse buying intention, mainly focusing on their influencing factors. Scholars pointed out that the main factors affecting consumers' online buying intentions are: network design, consumer' evaluation, convenience, promotion activities, merchant service level and creditworthiness. The reason for the impact of consumer' mobile online purchases is that shopping scenarios are characterized by personalization, entertainment, ubiquity, responsiveness, and socialization [3]. Factors that affect consumers' online cross-border purchase intention are: purchase cost, product quality, service quality, perceived risk, discount promotion, website externalities, etc.
[1]. Factors that influence consumers' online impulse purchase intention are: external stimulus factors, consumer' personal factors, situational factors, etc.

The special nature of the mobile e-commerce platform makes its external incentives different from other e-commerce platforms, even though the existing impulse buying research provides a new idea for online shopping promotion. Therefore, the existing research faces the following challenges when we want to systematically explain the impact mechanism of mobile cross-border imported e-commerce website features on consumer' impulse purchases: (1)Taking mobile website features as an external stimulus has been rare in previous scholar studies. (2)We have not simultaneously used the four variables of economics, personalise, socialization and interest as independent variables of website characteristics in the past to study the characteristics of e-commerce websites, which especially true in mobile site feature research. (3)Can emotion effectively explain the internal mechanism of external stimuli on consumers' impulse buying intention as an intermediary variable?

Therefore, this article intends to use the characteristics of the website to describe the impact of external stimuli on the impulse buying intention of mobile cross-border imported ecommerce platform consumers. A research model of "website characteristics $\rightarrow$ emotional responses $\rightarrow$ impulse buying intention" is established through defining four types of website characteristics of economical, personalise, socialize and interesting and two types of emotional mediators of pleasure and arousal. The article systematically reveals the influence of different website features on the impulse buying intention of mobile cross-border imported e-commerce platform consumers and the internal mechanism by taking the "mobile cross-border imported e-commerce platform" as an empirical research object and using Smart PLS software for data analysis.

\section{TheORETICAL Research AND Model Construction}

\section{A. Website Features and Impulse Buying Intention}

Consumers gradually develop the habit of using mobile devices for online shopping with the improvement of the level of mobile phone intelligence, the popularity of $4 \mathrm{G}$ networks and the continuous improvement of payment methods, which inevitably increases impulsive shopping in the context of 
mobile networks. Therefore, the impulsive purchase of mobile online consumers has become a hot issue in the study of online consumer behavior in the field of e-commerce. The study of mobile consumers' impulse buying behavior is less compared to the impulsive buying behavior in the traditional physical shopping environment. Scholars point out those consumers' impulse buying intentions and impulsive buying behavior are different and interrelated. Impulsive buying behavior refers to a kind of unplanned, unthinking and immediate purchasing behavior that the consumer generates a strong demand under the external stimulus and then produces an emotional state under this demand. Impulsive buying intention refers to the desire to buy a product immediately, strongly, unplannedly [2]. Studies have shown that purchase willingness is a reliable indicator of actual purchase behavior and there is a significant correlation between the two, although purchase intention is different from purchase behavior [4]. Therefore, this study uses impulsive purchase intention as an appropriate and effective alternative to impulsive buying behavior.

It is found that the characteristics of the website influence the important factors of the impulse buying behavior of consumers through the combing of related documents. Effective website features must match consumer' purchase motivation. Although there are many researches on consumer' purchase motivations in the existing research, the main online shopping motives are four types of motivations: motivation for novelty, motivation for cheapness, motivation for sociability, and motivation for entertainment. Economical website features, personalized website features, socialized website features, and interesting website features are common four types of websites features corresponded to different types of consumer purchase motives [5]. These site features significantly affect the consumer's purchase intention. This article defines the characteristics of website features and impulse purchase intention in combination with predecessors' research and mobile cross-border online purchase of imported goods scenarios as follows: (1)Economical website features refer to the degree of richness that the actual prices and price discounts, promotions and other preferential measures provided by the website. (2)Personalized website features refer to the degree of service that the mobile cross-border e-commerce platform recommends unique and suitable products for consumers based on the user's interest preference obtained after mining and processing massive user data. (3)Socialized website features refer to the degree of two-way information and emotional interaction that generated between consumers and other platform users through the functions of mobile cross-border imported e-commerce platform (sharing, recommendation, instant messaging, etc.). (4)Interesting website features refer to the degree of interest that the mobile cross-border import ecommerce platform uses high technology and various multimedia designs to give the site viewers.

The website recommendation system can greatly improve the user experience make consumers are willing to select and purchase products according to the information recommended by the mobile shopping platform [6]. Some researchers used the B2C shopping website as the object and explored the impact of the characteristics of the four websites on visual esthetic, interactive, information quality, and recommendation functions on impulse buying intentions of consumers. The economics of the website have an impact on the consumers' impulse buying intention. Different price discounts in the ecommerce platform have brought consumers a huge economic experience, which has impacted their online impulse purchases from the perspective of time-limited promotions [7]. In addition, individuals often make the same decisions as their friends and the normative influence can be achieved through the love of friends in a circle of friends. Therefore, many mobile cross-border e-commerce platforms have gradually launched community segments like We-Chat's friends. Platform users can exchange their own shopping experience and recommend good things each other. It is different from the general platform that there are many well-known net reds or stars among these platform users. They will share their beautiful log and interact socially with users in the comment area. It is not difficult to find that consumers will be more willing to buy their recommended products [8]. Based on the above analysis, this study proposes:

H1a: Economical website features has a positive effect on consumer' impulse buying intention

H1b: Personalized website features has a positive effect on consumer' impulse buying intention

H1c: Socialized website features has a positive effect on consumer' impulse buying intention

H1d: Interesting website features has a positive effect on consumer' impulse buying intention.

\section{B. Emotional and Online Impulse Buying Intention}

Today's shopping behavior has become a way for consumers to enjoy their entertainment. Mobile shopping is not limited in time and space to allow users to make full use of the fragmentation time for online shopping. The industry is paying more and more attention to the changes of consumers' sentiments in the process of mobile shopping, influenced by the characteristics of the virtual environment, and the influence of psychological emotions on impulse buying intentions. Emotion is a well-known word that is an individual's reaction and explanation to all factors and an apparently subtle behavior that occurs in a specific situation. It has a clear and systematic impact on the individual's psychological processes and behavior. Psychological emotion is an extremely complex physiological phenomenon caused by internal and external factors based on the results of previous research [9]. In terms of emotional dimensions, researchers have long pointed out that the "pleasure" and "arousal" two-dimensional components can explain the various characteristics of emotions and represent people's emotional responses to a wide range of environments without considering other dimensions. Pleasure is defined as a sense of joy, happiness, fun, and satisfaction. Arousal is defined as the feeling of individual stimulation, vitality, and excitement. Some scholars in China have also studied emotional responses in the mediating role of external stimuli and impulse buying. They also think that emotional reactions include pleasure and arousal two dimensions [10].

Therefore, this article will study the definition of emotion as an individual's strong and eager affective condition and its 
corresponding physical and behavioral expression. The emotions are summed up into two dimensions: pleasure and arousal. Pleasure refers to the effectiveness of emotional states, which from positive to neutral, to negative. Arousal refers to the power and intensity of the emotional experience, which from height to medium to low.

In addition to the final purchase result, the customer will still pursue inner emotional satisfaction in the process of mobile shopping. Therefore, consumers' psychological emotions have a positive effect on their purchase intentions. They enlarged their own needs and be too optimistic about their economic abilities when consumers are in a state of excitement. So it is easier to generate shopping impulses in such a happy state. They objectively evaluated their own needs for goods and focus on the target goods and made careful consideration of their purchase decisions when consumers are in a rational state. so they rarely generate unplanned purchase desires. If the intensity of such instinctive factors as emotions increases, it may cause impulsiveness. It can thus be seen that when consumers develop positive emotions, they will benefit the impulsive buying intentions of consumers. At the same time, emotional state plays an intermediary role in commodity image and online impulse buying intention. For example, a product image can positively and significantly affect the customer's emotional evoke. Pleasure and arousal can positively and significantly affect the online impulse buying intention. Many scholars have pointed out that a key factor influencing consumers' impulsive purchases is the emotional state of consumers [11]. Consumers' immediate joy will promote their impulsive purchases. In addition, previous studies have found that pleasure and arousal are closely linked. In other words, the higher the consumer's sense of arousal, the happier they feel. The more consumers are evoked and happier, the more likely they are to consume [12]. In the online environment, the arousal of individual dynamism has also proved to have a positive effect on pleasure [13]. Based on the above analysis, this study proposes:

H2a: Pleasure has an intermediary role in the impact of website characteristics on consumer' impulse purchase intention.

H2b: Arousal has an intermediary role in the impact of website characteristics on consumer' impulse purchase intention

H2c: Consumers' sense of arousal has a positive effect on their pleasure.

\section{Website Features and Emotions}

Because the mobile store has no display space restrictions, mobile online shops better meet the needs of consumers relative to the offline shops. Many niche brands or items that are not common in everyday life can be easily found online. For some overseas shops, consumers do not need to cross the ocean to go shopping. This part of demand can also be satisfactorily satisfied through online shopping with the rise of Haitao. Effective website features can stimulate the consumer's inner emotions and trigger their happiness and excitement. Researchers believe that website characteristics can affect the consumer's experience, thus affecting their reactions during web browsing process. As a stimulating factor of the external environment, the website features have an important influence on the consumer's emotional response. This shows that the characteristics of the website will have an impact on consumer sentiment.

\section{1) The Influence of Economical Website Characteristics} on Consumers'Emotion

One of the main reasons why consumers choose online shopping is that online stores can offer more favorable prices than physical stores. The price cuts, discounts, promotions and other preferential measures provided by the website can improve the economics of the website and bring real functional benefits to consumers. Foreign scholars have explored the impulsive purchase of apparel products in the context of the Internet and found that lower commodity prices make it easier for consumers to experience pleasant emotions when browsing websites, and thus the greater the possibility of impulsive purchases [14]. Instant discounts provided by the website can increase the attractiveness of prices and promote impulse buying by enhancing consumers' sense of arousal and pleasure. Consumers with low self-control ability will have a strong emotional reaction under low price stimulation [13]. Domestic scholars through questionnaire surveys and data analysis have found that the economical website characteristics have a significant positive effect on the perceived pleasure of consumers. Based on the above analysis, this study proposes:

H3a: The economical website characteristics have a positive effect on consumer's pleasure

H3b: The economical website characteristics have a positive effect on consumer's arousal

\section{2) The Influence of Personalized Website Characteristics} on Consumers'Emotion

In most cases, each mobile device has a unique owner, which means that the operations on this device correspond to the behaviors of the respective users, such as payment habits, consumer preferences, and so on. This information is of value to the merchant. The merchant can provide personalized services according to each user's behavior. The personalized website characteristics can help the mobile shopping platform to send information based on the individual needs of each user to achieve one-to-one marketing. Therefore, the factors of ubiquity and individuation are the characteristics of mobile buying situation. The research finds that ubiquitous and personalized features will significantly affect consumers' willingness to buy through emotional experience. Personalized services based on location and demand information push reduce consumer efforts in the information search process and improve shopping pleasure and sense of control, and thus arousal strong consumer willingness to purchase. The personalized service of the website can provide targeted product recommendations according to the user's personal preferences, greatly reducing the user's time cost, enabling the user to feel joyful and motivated in selecting and purchasing the merchandise, resulting in emotional value [15]. Matching consistency improves fluency and makes consumers happy. Based on the above analysis, this study proposes: 
H4a: The personalized website characteristics have a positive effect on consumer's pleasure

H4b: The personalized website characteristics have a positive effect on consumer's arousal

3) The Influence of Socialized Website Features on Consumers'Emotion

Mobile devices are essentially social devices. People use mobile social applications on mobile devices or social functions of mobile online shopping platforms to conduct realtime discussion and communication with others and to view others' evaluations and sharing, which make mobile online shopping situations appear, socialized. Due to factors such as mobile cross-border imported e-commerce users purchasing fragmentation, small mobile device screens, etc., consumers do not like to search and browse too much information. Consumers like to use the sharing recommendation function on the mobile online shopping platform to discuss and communicate with others in real time, and prefer to quickly and directly obtain the information they need in the evaluation, sharing, and recommendation of opinion leader users, which also makes the mobile online shopping situation appear social features. Communication and communication between consumers in the virtual space. This kind of joyful interpersonal communication enables consumers to lay down their hearts and makes it is easy to browse online stores and create a happy mood [16].

In addition, when consumers refer to the purchase, use, and evaluation of products and brands by others, they also have immediate joy [17]. On the other hand, many online red or stars have entered the mobile cross-border import e-commerce platform. They not only play the role of opinion leaders on the platform to recommend suitable products for consumers, but also exchange shopping experiences with consumers like friends. These opinion leaders also have important influence on the emotional state of consumers. Based on the above analysis, this study proposes:

H5a: The socialized website characteristics have a positive effect on consumer's pleasure

H5b: The socialized website characteristics have a positive effect on consumer's arousal

4) The Influence of Interesting Website Features on Consumers'Emotion

From the perspective of consumers, that is, consumers feel the joy of mobile online shopping. The gamified interface and interesting promotional activities on the mobile online shopping platform make consumers more interested in browsing. The most important experience for consumers when shopping on mobile is to enjoy the shopping process. The popularity of these smart mobile terminals makes them an important channel for consumers to shop since mobile devices such as mobile phones and tablet PCs are mainly for entertainment purposes or pass the time for users. Therefore, whether or not the shopping situation is interesting has become an important factor that influences consumers to make purchase decisions. The entertainment of the website has a positive effect on consumer sentiment in mobile shopping. If the mobile service provider can provide interesting, novel, unique, and experiential information or activities that inspire consumers' intense curiosity and interest, consumers will focus on the shopping activities of the website and be more pleasing, which easier to produce a pleasant experience[18]. The more novel and unique the event content or information presented by the website, the more focused the consumer is on the website activity, the more emotional experience will be generated [19]. The UI design, music, and animation of website can bring consumers different levels of entertainment. "Shake it, send red envelopes" and other marketing methods also allow consumers to experience the fun of the shopping process. The fun mobile shopping platform can enrich the emotional experience of consumers during shopping and make consumers feel that this is a fun and exciting shopping experience. It can be seen that the fun of the shopping platform is conducive to the formation of consumer emotions. Based on the above analysis, this study proposes:

H6a: The interesting website characteristics have a positive effect on consumer's pleasure

H6b: The interesting website characteristics have a positive effect on consumer's arousal

\section{The Regulatory Effect of Online Reviews}

The greater the influence of consumers, the more likely it is to create unplanned or even unthinking impulse purchases. Online shopping makes it easier for consumers to understand other people's opinions. Positive online reviews can influence consumer decisions and negative online reviews have a greater impact on consumers [14]. Some scholars have proved that online reviews can regulate the relationship between consumer's sense of pleasure and impulsive buying intention. The new generation of consumers tends to be less inclined to make their own decisions and rely more on product reviews on digital media [20]. There are also experimental design methods to study the impact of contradictory online reviews on purchase decisions, pointing out that online negative reviews have a significantly greater effect on consumer purchase decisions than positive reviews. It is generally believed that when the polarity of online reviews becomes more positive, the stronger the tendency of self-impulse purchases, the less the emotional impact on impulse buying. On the contrary, when the polarity of online reviews becomes more negative, consumers are more likely to rely on clarification to make impulsive purchase decisions and the impact of emotion on impulse purchases is strengthened. Based on the above analysis, this study proposes:

H7a: Online reviews have a moderating effect on the relationship between consumer's pleasure and impulsive buying intention

H7b: Online reviews have a moderating effect on the relationship between consumer's arousal and impulsive buying intention

\section{E. Research Framework}

The stimulus-body-response model (S-O-R model) was first proposed by scholars in the 1970s. Marketing experts applied the S-O-R model to the traditional retail environment as early as possible, and on this basis, discussed the influence of the 
store environment on the customers' purchase intention and behavior. Scholars at home and abroad have begun to apply the $\mathrm{S}-\mathrm{O}-\mathrm{R}$ model to research on the impact of Internet environment on consumer' impulse purchases with the continuous development of network technology, the e-commerce platform is increasingly perfected, and the scale of network consumption has grown rapidly. It is mainly used to try to explain the influence of the physical environment on human behavior. The model consists of three-dimensional degrees including antecedent variables (external environment), mediator variables (emotional states or emotional states), and reaction behaviors (achieved or circumvented output outcomes). The S-O-R model considers individuals affected by the external environment to be approached or circumvented by the individual's emotional state. Combining the above analysis, this study will use four types of economical, personalized, socialized and interesting site features as models for external stimuli (S), emotions (pleasure and arousal) as body (O) and impulsive buying intention as a response (R). We tentatively explored the impact of mobile cross-border import e-commerce virtual environment characteristics on consumers' psychological sentiment considering the regulatory role of ecommerce platform online review, which affecting the whole process of impulse buying intention formation. Finally, as shown in the following figure, we will establish a research model for the impact of consumer' impulsive buying intentions on mobile cross-border imported e-commerce platforms

\section{External Stimuli ( $\mathbf{S}$ )}

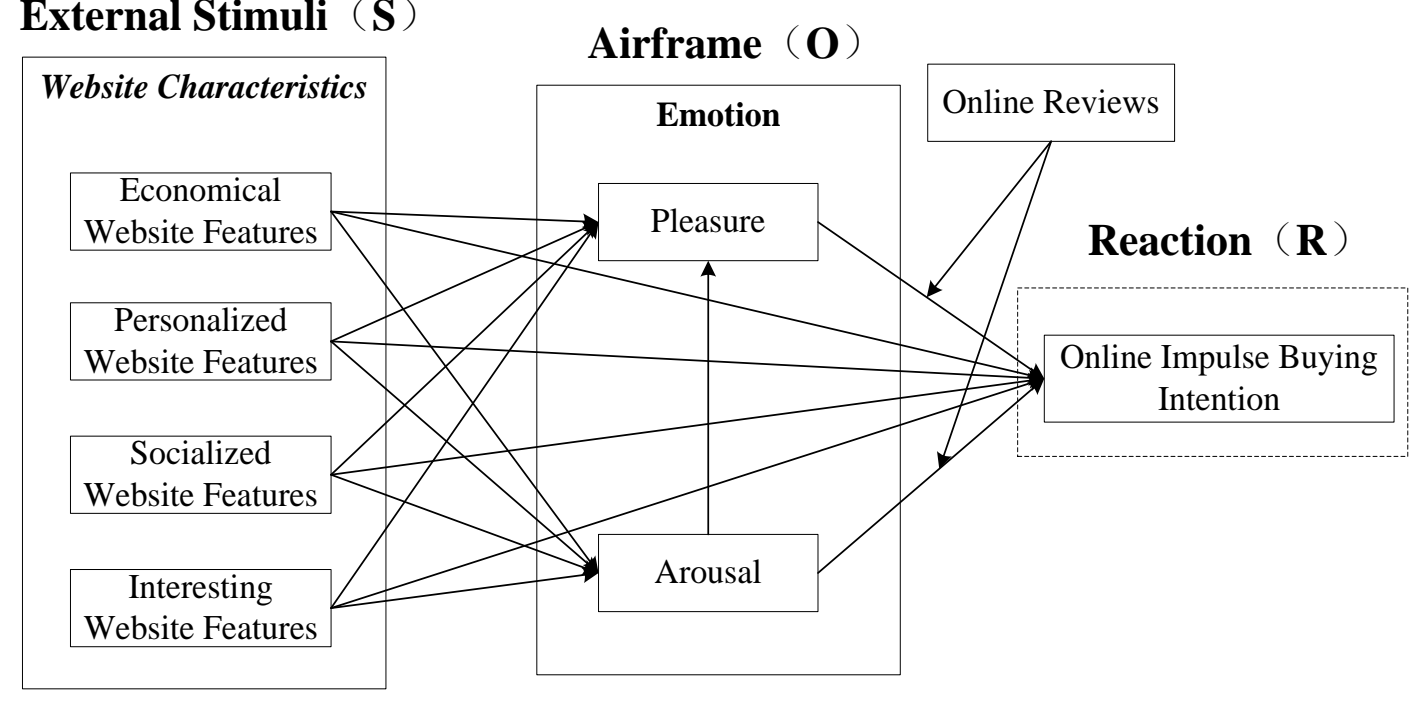

Fig. 1. Model of influence factors on of consumers' impulse buying intention based on mobile cross-border imported e-commerce platform

\section{CONCLUSIONS AND Follow-UP ReseARCh Plans}

Consumer impulse buying intention is influenced by many factors. This paper constructs a model of consumer impulse buying influence factors based on cross-border imported ecommerce platform by adopting the general research method of S-O-R model and combining the mobile shopping situation. From a theoretical point of view, we conduct reasonable reasoning combined the characteristics of cross-border imported e-commerce platforms and mobile commerce technologies. Web site features are classified as economic, personal, social, and interesting and we redefine the characteristics of specific websites. Consumer emotions are divided into pleasure and arousal combined relevant theories and existing research in consumer' impulse buying to further improve the consumer-immune-body-response (S-O-R) of consumer' impulse buying willingness analysis chain.

Follow-up research is planned to be carried out in the following aspects: (1) Drawing on existing literature and scales to optimize measurement tools and questionnaires, and conduct a large-scale survey on mobile cross-border imported ecommerce platforms. The statistical method based on the structural equations is used for data analysis. The model is empirically tested and the data is fitted with other analytical tools. Relevant policy recommendations are proposed based on the research results. (2)Focus on the characteristics of social networking sites; study the boundaries of social objects affecting consumers' emotional perception and the relationship between consumers and social objects. (3)Differentiating the characteristics of different shopping platforms, we will focus on in-depth research on the factors affecting the impulse buying intention of mobile cross-border imported e-commerce platforms.

\section{ACKNOWLEDGMENT}

This article is one of the phased achievements of the National Social Science Fund's major tendering project "Research on Big Data Based Cross-border E-commerce Monitoring, Evaluation, and Supervision System"(16ZDA053).

\section{REFERENCES}

[1] Li Linghui, Cao Shuyan. Research on the Influencing Factors of B2C Cross-border E-commerce Consumers' Purchase Decision[J]., International Business (Journal of University of International Business and Economics), 2017 (1): 151-160.In Chinese

[2] Mwencha P. M., Muathe S .M., Thuo J. K. Effect of Perceived Attributes, Perceived Risk and Perceived Value on Usage of Online 
Retailing Services[J]. Journal of Management Research, 2014,6(2) : 140-161

[3] Floh, A., Madlberger, M. The Role of Atmospheric Cues in Online Impulse-Buying Behavior[J]. Electronic Commerce Research and Applications,2013, 12(6): 425-439.

[4] Rigollet D Ý, Kumlin H. Consumer Attitudes towards Push Notifications : As a Marketing Tool to Trigger Impulse Buying Behaviour in Smartphone Users[J]. Applied Physics Letters, 2015, 74(16):2355-2357.

[5] Chung S, Kim K. An Empirical Study on the Influencing Factors of Perceived Job Performance in the Context of Enterprise Mobile Applications[J]. Asia Pacific Journal of Information Systems, 2014, 24(1):31-50.

[6] Aljukhadar $M$. Usage and success factors of commercial recommendation agents: A consumer qualitative study of MyProductAdvisor.com[J].Journal of Research in Interactive Marketing, 2011,5(2):130-152.

[7] Liao SL, Shen YC, Chu Cll. 'The effects of sales promotion strategy, product appeal and consumer tralts On reminder impulse buylng behaviour[J].lntemational ,Journal of Consumer Studies 2009, 33 (3):274-284

[8] Quiet, Zheng Rong, Zeng Xinyong. A study on the influence of online opinion leaders on the purchase behavior of female consumers [J]. Business Economics Research, 2015 36: 59-60.

[9] Droitvolet S, Berthon M. Emotion and Implicit Timing: The Arousal Effect:[J]. Frontiers in Psychology,2017, 8(337):176.

[10] Chang Yaping, Xiao Wanfu, Qin Wu, et al. The influence mechanism of third-party reviews on impulse purchase intention under the network environment: product category and commentator level are the regulating variables [J].Acta Psychologica Sinica, 2012, 44(9):1244-1264.In Chinese
[11] Nair D, Das S. Impact of Emotional Intelligence on Impulse Buying and Product Value Proposition[J]. IEEE Geoscience \& Remote Sensing Letters, 2015, PP(99):1-5.

[12] Tong L, Xi C, Chen Y. The effect of website characteristics on online impulse buying[J]. Journal of Zhejiang University, 2017.

[13] Wang Qiuzhen, Yao Qian, Ye Ying. A study on the influence Mechanism of Price discount and the number of buyers on consumers' impulsive purchase willingness under the Network Group purchase scenario [J]. Journal of Management Engineering, 2014,2810: 37-47.In Chinese

[14] Park, C., and T. M. Lee, “Information direction, website reputation and eWOM effect: A moderating role of product type,” Journal of Business Research,vol. 62,no. 6( 2009) ,pp. 61- 67

[15] Dai Debao, Liu Xiang, and Ruozhoujun. A study on the factors influencing the willingness of Personalized recommendation and Adoption in the Internet era [J]. China Soft Science, 2014(5):64-73.In Chinese

[16] Chevalier J., Mayzlin D. The effect of word of mouth on sales: online book reviews[J], Journal of Marketing Research,2006, 43(8), 345-354.

[17] Tsai W H S, Men L R. Social CEOs: The effects of CEOs communication styles and parasocial interaction on social networking sites[J]. New Media\&Society, 2016, 5(3):1-20.

[18] Han Chaoqun, Yang Shuiqing, Cao Yuzhi. An Integrated Model of Mobile Service User Adoption Behavior-An Empirical Study Based on Mobile Reading. Soft Science, 2012, 26(3):134-139.In Chinese

[19] Fard S S, Tamam E, Hassan M S H, et al. Factors affecting Malaysian university students' purchase intention in social networking sites[J]. 2016, 3(1):1182612.

[20] Fagerstrøm A, Gh inea G, Sydnes L. Understanding the Impact of On line Reviews on Customer Choice: A Probability Discounting Approach[J]. Psychology \& Marketing, 2016, 33(2):125-134. 